\title{
THE DEVELOPMENT OF ALIGNED COLUMNAR SEA ICE: A FIELD INVESTIGATION
}

\author{
By Ed Stander and Bernard Michel
}

(Département Genie Civil, Université Laval, Québec City, Province Québec G1K 7P4, Canada)

\begin{abstract}
The development of strong preferred $c$-axis alignments in sea ice has been a subject of debate since its initial discovery in 1959. Although numerous theories have been proposed for its development, none has been able to account for all of its field characteristics.

A detailed field investigation was carried out at Pond Inlet, N.W.T., to describe further the occurrence and structure of this ice type. Data collected over the winter of 1983-84 suggest two possible mechanisms of development. The first involves the selective growth of crystals during the formation of the initial ice skim, while the second requires the solid-state rotation of slip planes during constrained plastic deformation.
\end{abstract}

\section{INTRODUCTION}

Sea-ice sheets typically consist of two horizontally stratified layers. The upper, or "polycrystalline" layer, is usually the thinner of the two, and consists of randomly oriented, fine-grained crystals formed by the turbulent mixing of surface waters, or the direct precipitation of frozen spray and snow. The thickness of this layer depends on surface conditions at the time of freeze-up, and typically ranges from 1 to $25 \mathrm{~cm}$.

The lower, or "columnar" layer, forms gradationally from the upper layer by the rapid growth of those crystals which are in a preferred orientation for growth (i.e. those that have their basal planes perpendicular, and crystallographic $c$-axes parallel to the growing interface). All other crystal orientations are wedged out with depth, so that the ice sheet gradually develops a columnar structure with preferred horizontal $c$-axes (Perey and Pounder, 1958). This columnar layer makes up the bulk of most sea-ice sheets and is usually continuous to the base of the ice cover.

While this wedging-out process may produce columnar crystals with horizontal $c$-axes, it cannot directly explain why these crystals often display a strong $c$-axis alignment in the horizontal plane. This peculiar ice type, hereafter called aligned columnar or " $\mathrm{C}_{3}$ " sea ice, has been reported by numerous authors, and appears to have nearly as many hypotheses for its development. In the present paper, the available field observations pertaining to the formation of aligned columnar sea ice are reviewed, and new observations are presented which shed further light on the forces responsible for its development.

\section{PRINCIPAL FEATURES OF ALIGNED COLUMNAR SEA} ICE

Aligned columnar ice sea has been found over much of the Arctic region, including parts of the Beaufort Sea (Peyton, 1966; Weeks and Gow, 1978, 1980; Vittoratos, 1979; Wang, 1979; Langhorne and others, 1980), Kara Sea (Cherepanov, 1971), Greenland Sea (Tucker and others, 1985), and scattered localities in the Canadian Archipelago (Parsons and others, 1986; Stander, unpublished). It has been observed by the author in the temperate ice sheet developed off Newfoundland, Canada, and has been noted at Mirnyy Roads (Serikov, 1962), McMurdo Sound (Paige, 1966; Gow and others, 1982), and Lützow-Holmbukta (Urabe and Inoue, 1986), Antarctica. Overall, it appears to be one of the most extensively developed ice types to occur over the world's cold oceans.

Notwithstanding these observations, there have been numerous published reports marking its absence. Smith (1964), for example, noted that aligned columnar sea ice was only developed locally in the ice sheet surrounding ARLIS II ice island, while Paige (1966) and Reimer (unpublished) both reported that aligned columnar ice could only be found in the vicinity of small pressure ridges. Interestingly enough, in both of these latter instances, aligned ice was found to be developed ubiquitously during subsequent visits to the same localities (Gow and others, 1982; Stander, unpublished), suggesting that certain environmental conditions must be met to initiate the development of this ice type.

Aligned columnar sea ice is usually thought to develop with depth from an initially non-aligned columnar layer (Peyton, 1963; Weeks and Gow, 1978; Langhorne and others, 1980). The transition from unaligned columnar to aligned columnar ice usually occurs at a depth of $30-60 \mathrm{~cm}$ (Peyton, 1963; Weeks and Gow, 1978, 1980; Langhorne, unpublished), although Serikov (1962) noted well-developed $c$-axis alignments immediately below the polycrystalline layer. Below this depth, $c$-axis alignment improves linearly to the point where all $c$-axes in the ice sheet lie within $20-40^{\circ}$ of one another and the ice sheet effectively becomes an enormous single crystal.

Once formed, $c$-axis alignments do not appear to change orientation with depth, unless the columnar crystals are first capped by a layer of frazil ice.

\section{THE POND INLET FIELD PROGRAM}

Since its initial discovery in 1958, the development of aligned columnar sea ice has been ascribed to five processes: bi-directional thermal gradients (Weeks and Lee, 1958; Schwarzacher, 1959), the Earth's magnetic field (Cherepanov, 1971), wind stresses operating on the initial ice skim (Cherepanov, 1971), under-ice current activity (Cherepanov, 1971; Weeks and Gow, 1978), and deviatoric strains operating in the plane of the ice sheet (Paige, 1966; Peyton, 1966). However, no theory based on these processes has yet been able to account for all of its field characteristics.

In the present study, the formation and growth of aligned columnar sea ice was studied in order to define which of the above processes was most important to its development. Pond Inlet, a small community on Baffin Island, Canada, was chosen as the site of investigation due to the variety of ice types present near the settlement, as well as the logistical and scientific support locally available through the Arctic Research Establishment of Pond Inlet.

Freeze-up during the winter of 1983-84 was marked by several events, commencing with the arrival of two icebergs (Bergs 1 and 2) early in October. Shortly after, on the night of 18 October, Eclipse Sound skimmed over and the first ice cover of the year formed. However, this ice cover was short-lived, as a storm on 30 October broke up the sheet and cleared much of Eclipse Sound of ice. 
First-year pack ice subsequently drifted into the area, and became trapped during the second general freeze-up on the night of 1 November. By the first week of November, this ice sheet had stabilized, and leads had begun to develop about the two icebergs. By 10 November, shore-fast ice, pack ice, refrozen lead ice, and grounded glacier ice could all be found within $3 \mathrm{~km}$ of town (Fig. 1).

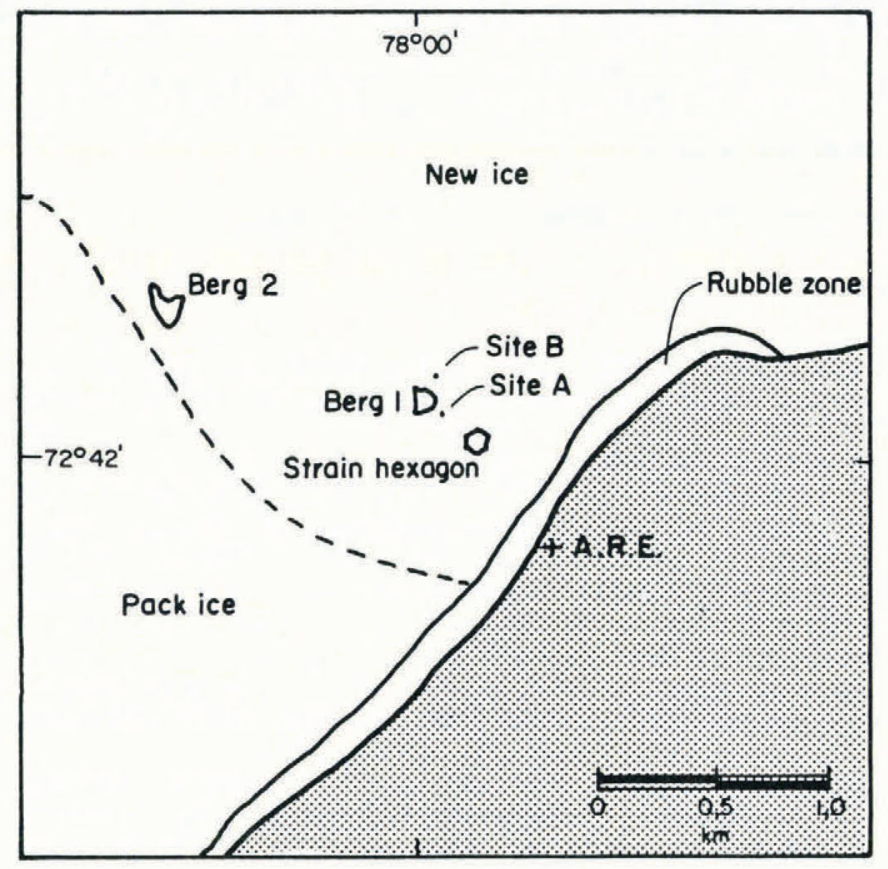

Fig. 1. General location map for the Pond Inlet field study.

\section{METHODOLOGY}

Three occupations were made of the Pond Inlet site during the 1983-84 field season. The first occurred between 10 and 15 November 1983 and concerned itself with equipment deployment and preliminary coring. The second occupation took place from 23 November to 4 December, during which time salinity measurements and cores were taken. The third occupation occurred between 3 and 16 May 1984 and involved the analysis of cores and current measurements in the vicinity of Berg 1 .

A total of 1274 in $[10 \mathrm{~cm}]$ diameter cores were analyzed during the study, all of which were oriented with respect to surveyed base lines. Twenty-eight cores were taken during the early winter and 99 were collected in May. Thin sections were made of the lower $10 \mathrm{~cm}$ and upper $20 \mathrm{~cm}$ of each core, with occasional sections made half-way down the length of the core. Five representative cores were further analyzed at $10 \mathrm{~cm}$ intervals, and one core was thin-sectioned and photographed at intervals of $1 \mathrm{~cm}$. The large grain-size and extreme alignment observed in nearly all cores precluded their analysis on the universal stage.

Ice displacement and strain were measured from a surveyed hexagon $50 \mathrm{~m}$ on a side located $470 \mathrm{~m}$ offshore (Fig. 1). The apices of this hexagon were marked by aluminum platforms, $1.3 \mathrm{~m}$ high, upon which an EDM/ theodolite (Wild DI20/T2) combination, or EDM reflector could be positioned. The accuracy of mounting was in the order of $\pm 1 \mathrm{~mm}$, and the measurement accuracy was $5 \mathrm{~mm}$ and $3^{\prime \prime}$ of arc, respectively. Measurements of ice displacement were made on 14 November, 15 November, 4 December, and 6 May. Subsequent calculations of finite strain were made with respect to the 14 November data set, and only those values which were internally consistent were plotted.

Detailed salinity measurements were made on two cores, one collected on 12 November, the second on 24 November. Salinity measurements accurate to $0.05 \% \mathrm{NaCl}$ were made at A.R.E. using a Blucher-Cotline titration chloridometer. All other salinity measurements were made by the staff of A.R.E. using an ENDECO optical salinometer.

Two sets of current measurements were made during the study; one during the period $8 \rightarrow$ May 1984, and the second during 11-12 May 1984. On both occasions, an Aanderaa Arctic-type current meter was suspended $80 \mathrm{~cm}$ beneath the base of the ice sheet on a metal rod, and oriented with respect to survey markers. Measurements were made at $15 \mathrm{~min}$ intervals and analyzed at the Arctic Research Establishment.

\section{RESULTS}

\section{Displacement and strain measurements}

Ice displacement during the measurement period (14 November-6 May) was generally offshore, and deflected slightly in the direction of the prevailing current. The rate of offshore movement increased linearly during the winter, and followed a similar trend to that recorded in 1982-83 (Fig. 2a). Shore-parallel movement decreased logarithmically during the same period according to the equation:

$$
Y=-2.142+0.829 \ln X
$$

which compares favorably to data acquired the previous year (Fig. 2b).
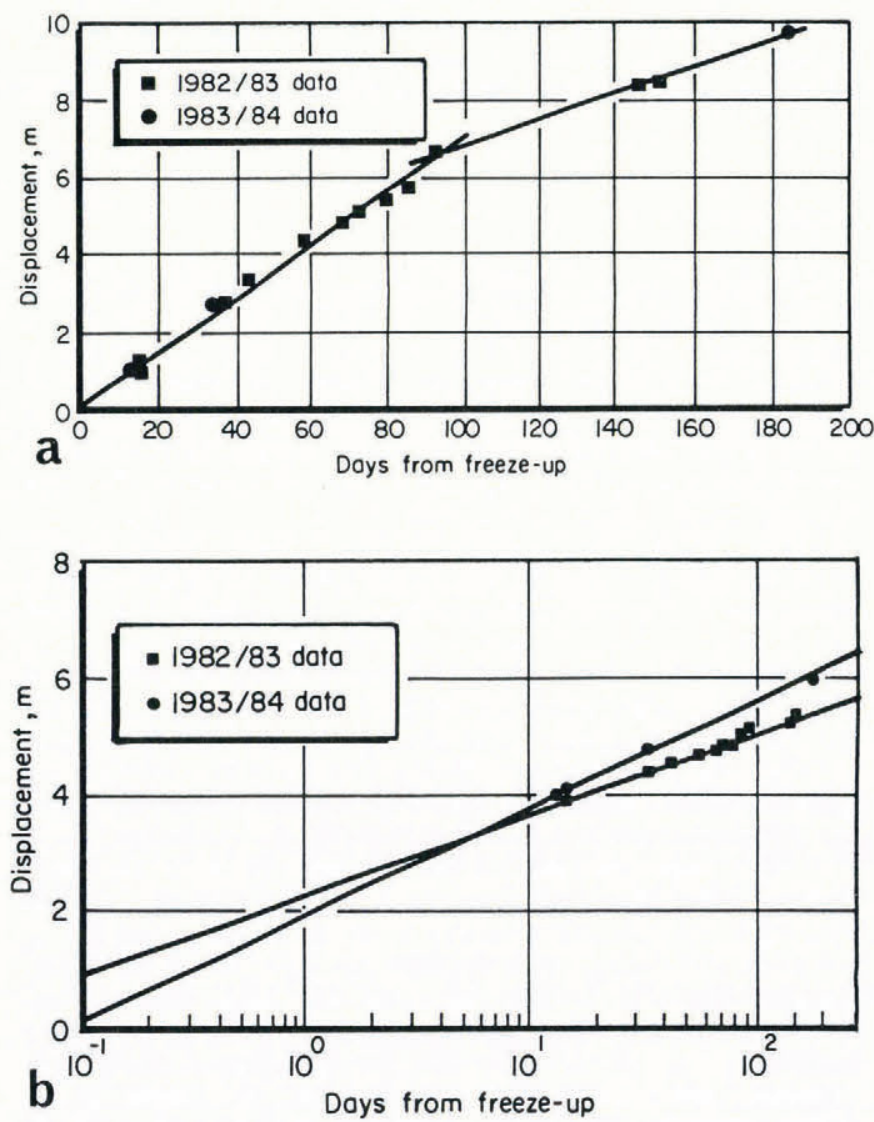

Fig. 2. Ice displacement $1 \mathrm{~km}$ offshore of Pond Inlet. Figure $2 a$ gives the offshore component of ice movement. while Figure $2 b$ gives the shore-parallel component.

Finite strain during each of the measurement intervals was consistent and low. The average strain-rate during the period 14 November- 6 December was $4.5 \times 10^{-10} \mathrm{~s}^{-1}$, and this slowed to $8.0 \times 10^{-11} \mathrm{~s}^{-1}$ by May. Total finite strain during the study period amounted to $0.22 \% \quad(2200$ microstrains), comparable to measurements acquired during the previous year (Stander and others, 1988; Stander, unpublished). The direction of maximum shortening was consistent throughout the measurement period, and lay $\mathrm{N} 25^{\circ} \mathrm{W}\left( \pm 10^{\circ}\right)-$ approximately perpendicular to the axis of Eclipse Sound. 
Ice structure and crystallography

General structure

The Pond Inlet ice sheet during the winter of 1983-84 was generally continuous and of low relief, apart from the near-shore zone where the sheet was hummocked by grounded multi-year floes (Fig. 1). Leads were locally developed, but not common. Their development was restricted to the ice cover adjacent to Bergs 1 and 2 , and the near-shore tidal hinge zone. Leads developed in the vicinity of the grounded icebergs extended radially outwards from the icebergs and were $1-2 \mathrm{~m}$ wide. Most formed during the early winter, when the ice sheet was less than $1 \mathrm{~m}$ thick. Leads in the tidal zone lay parallel to the shore and were operative throughout the study period. No compressive structures were noted, apart from local ice ramps which formed in the vicinity of Berg 1 late in the season.

\section{The new ice sheet}

At the time of first coring (10 November), the new ice cover was $42 \mathrm{~cm}$ thick, and exhibited a well-developed platelet layer extending $1.5 \mathrm{~cm}$ from the bottom of the ice sheet. By the end of the second occupation (4 December), the ice sheet had increased in thickness to $59 \mathrm{~cm}$, and by May, the ice sheet averaged $185 \mathrm{~cm}$, with a freeboard of $13 \mathrm{~cm}$, and $10 \mathrm{~cm}$ of overlying snow.

The most striking feature of those ice cores collected during the early winter (10 November-4 December) was a horizontal banding formed by the interlayering of clear and

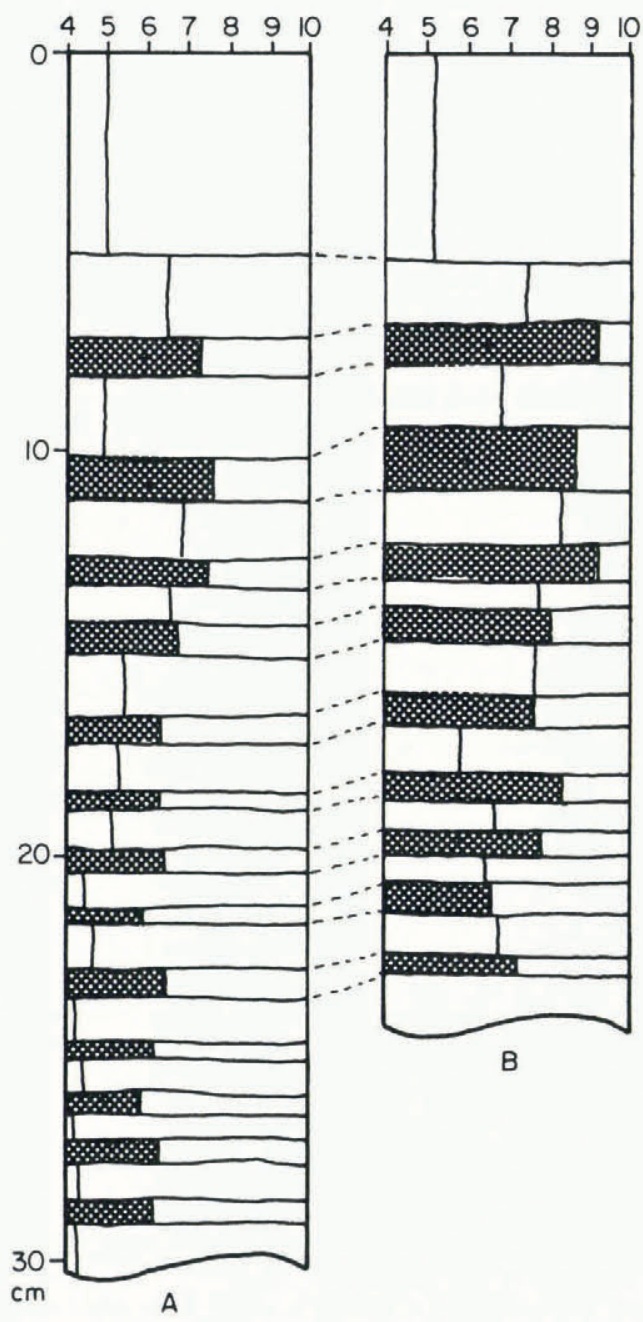

Fig. 3. Structure and salinity of two cores collected on (a) 12 November, and (b) 24 November 1983. The cloudy zones are stippled in this diagram, and salinity in ppt is provided by the vertical lines. cloudy ice zones. These alternating bands were found in all cores studied, and could be traced between cores (Fig. 3). Their formation was restricted to the first $15 \mathrm{~d}$ of ice growth, during which time they developed at a measured rate of one band every $6 \mathrm{~h}$.

The contact between the cloudy and clear bands varied in structure over the study period. During the first occupation, the upper surface of each cloudy layer was sharply defined, while the lower contact with the clear layer was gradational. By the end of November, both upper and lower contacts had become diffuse and gradational, and by 3 May no layering was apparent. Detailed salinity measurements of each layer showed that the cloudy layers were generally brine-enriched when compared to the clear layers, but that this salinity difference was lost as the bands became more diffuse (Fig. 3).

The rate of ice growth during the period $1-13$ November was calculated from band-thickness measurements acquired from five cores. These calculations show that the ice sheet thickened at a nearly constant rate of $3 \mathrm{~cm} / \mathrm{d}$ after an initial period of rapid ice growth $(6-10 \mathrm{~cm})$ during freeze-up (Fig. 4)

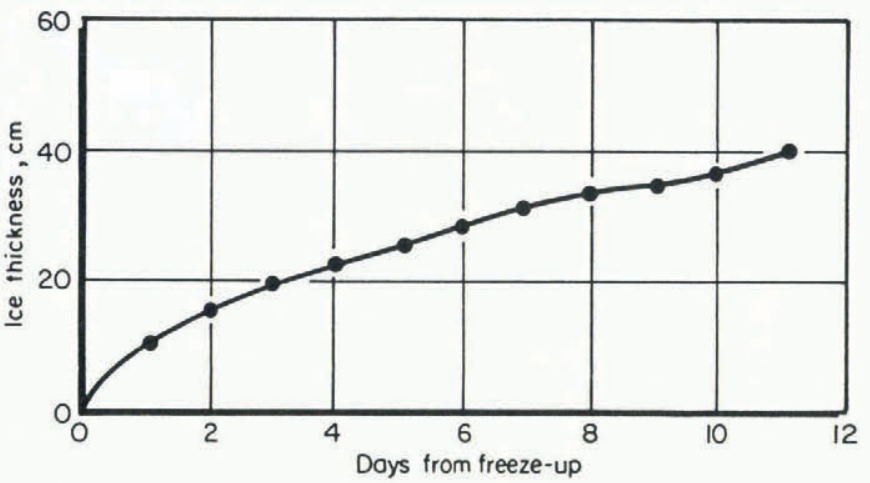

Fig. 4. Growth history of the Pond Inlet ice sheet as inferred from the growth zones of Figure 3.

Vertical and horizontal thin sections of the new ice sheet showed it to be quite homogeneous. Apart from a $2-5 \mathrm{~cm}$ thick frazil layer, the ice sheet from top to bottom consisted of aligned columnar ice interspersed by small, randomly oriented crystals. Ice columns were continuous from the ice surface to depth, and varied in size from $2 \mathrm{~cm}$ by $4 \mathrm{~cm}$ by $15 \mathrm{~cm}$ at the nucleating layer to $2 \mathrm{~cm}$ by $6 \mathrm{~cm}$ by $20 \mathrm{~cm}$ at the base of the ice sheet. The columns extended through the cloudy and clear layers without offset, although there tended to be a larger number of small, randomly oriented grains in the cloudy bands. Intercrystalline microstructures, such as beheaded sub-grains, slip bands, and serrated grain boundaries (Stander, 1985) were all present in the upper part of the ice sheet by the end of November.

Only one core, collected from the lee of Berg 1, exhibited a random frazil texture over its entire length.

\section{The pack ice}

The ice floes located just east of Pond Inlet comprised the remnants of the ice sheet lost during the storm of 30 October. They were generally $2-4 \mathrm{~m}$ in diameter and $30-40 \mathrm{~cm}$ thicker than the surrounding new ice.

Cores taken from the ice floes could be visually separated into three distinct units. The upper $40 \mathrm{~cm}$ (apart from a $3 \mathrm{~cm}$ thick frazil layer) consisted of columnar grains similar in dimensions to those in the new ice sheet, but lacking the strong shape and $c$-axis anisotropy noted in the new ice. Cloudy bands were prevalent and very thick (average $4-5 \mathrm{~cm} /$ band), but no attempt was made to correlate them between floes.

At a depth of $40-45 \mathrm{~cm}$, the columnar grains were abruptly capped by a $30 \mathrm{~cm}$ thick frazil layer believed to have formed during ice transport to Pond Inlet. The frazil crystals were extremely small, and appeared to be randomly oriented, although their size precluded any detailed study. 
Columnar grains underlay the frazil zone and extended to the base of the floe (average $87 \mathrm{~cm}$ in December, 205 $\mathrm{cm}$ in May). In the majority of cases, these columnar grains lacked any discernible shape or crystallographic alignment, although one floe exhibited as strong a preferred $c$-axis alignment as that found in the surrounding new ice. In this core, aligned columnar ice developed within $2 \mathrm{~cm}$ of the frazil layer, and retained a strong alignment to depth.

Spatial variations in c-axis alignment

Of the 127 cores collected during this study, only one core in the new ice sheet and six from the pack-ice zone did not display a strong $c$-axis alignment. The degree of orientation at all other sites was extreme, with the majority of $c$-axes in a given sample lying within $20^{\circ}$ of a mean orientation. The direction of $c$-axis alignment generally lay parallel to the Pond Inlet shoreline, although major deviations from this orientation were noted in the vicinity of the two grounded icebergs, and in the pack-ice zone.

$c$-axis alignments in the ice cover surrounding Bergs 1 and 2 varied systematically about the structures (Fig. 5). Deflections of $\pm 25^{\circ}$ were found on the southern

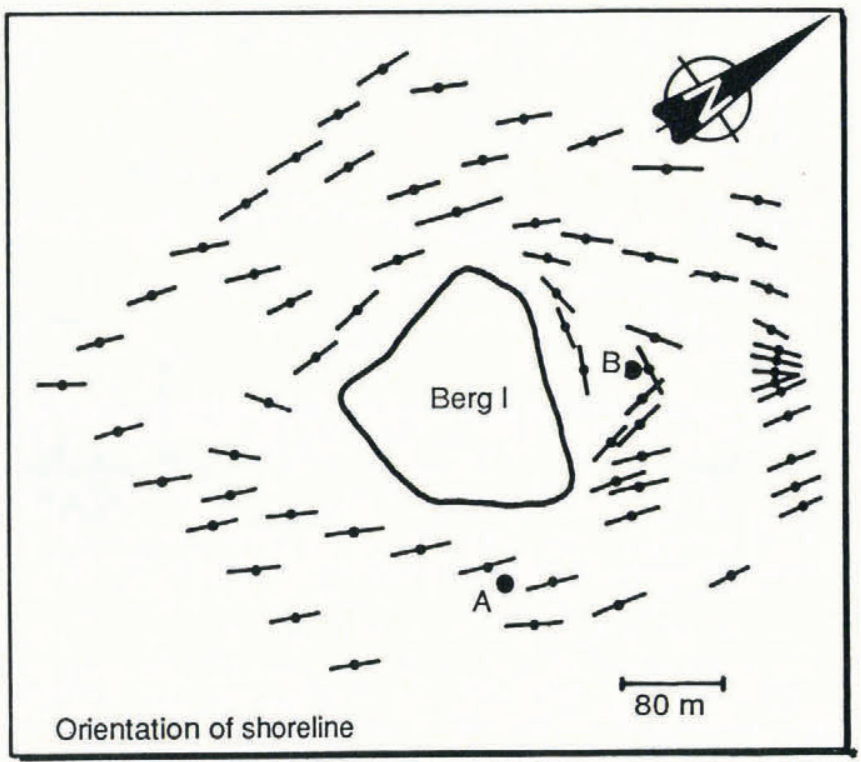

Fig. 5. c-axis variations noted about Berg 1. In this sketch, the principal current flows towards the north-east.

(currentward) side of the icebergs, while systematic deflections of up to $90^{\circ}$ occurred on the northern (or leeward) side. The observed $c$-axis pattern was bilaterally symmetric, with the plane of symmetry lying parallel to the Pond Inlet shoreline.

Aligned columnar ice in the pack-ice zone was only observed at one location, where it lay at a high angle to the shore. Non-aligned columnar ice prevailed at all other cored sites.

\section{Current measurements}

Current measurements were acquired for two sites during the May occupation. Site A was located $50 \mathrm{~m}$ due east of Berg 1, and lay directly in the path of the prevailing current in Eclipse Sound. Site B was located $60 \mathrm{~m}$ north of Berg 1, and lay within the current shadow of the iceberg. A total of $21215 \mathrm{~min}$ averaged measurements were taken at site $\mathrm{A}$, and 184 measurements were collected at site B. Measured current velocities and directions are presented in Figure 6. The average $c$-axis alignment at each site is also provided for reference.

In general, current activity was much greater at site A than at site $B$. The average current velocity at site A was $17 \mathrm{~cm} / \mathrm{s}$, and the average direction was $\mathrm{N} 10^{\circ} \mathrm{W}$, parallel to the $c$-axis alignment at the ice-water interface. In contrast, the current velocity at site B averaged less than $3 \mathrm{~cm} / \mathrm{s}$, and the direction of current movement fluctuated widely between readings; yet, in spite of this, strongly aligned

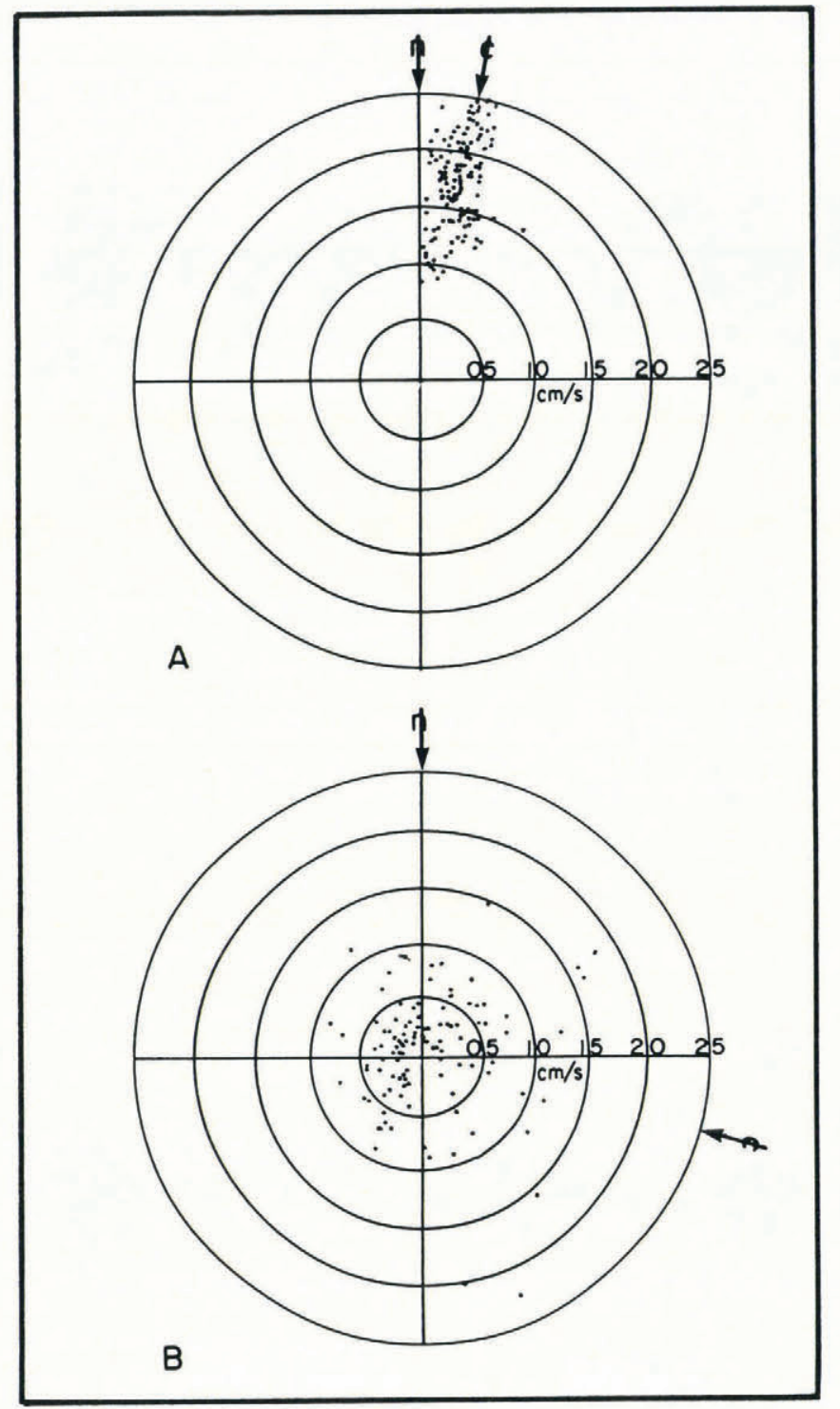

Fig. 6. 15 min averaged current measurements from sites $A$ and $B$. North is defined by the arrow at $0^{\circ}$ azimuth, and the mean c-axis orientation determined at the time of current measurement is given by the second arrow.

columnar ice was present at this site, with the mean $c$-axis orientation lying nearly perpendicular to that observed at site A.

\section{DISCUSSION}

Of the five possible models for alignment mentioned above, most may be dismissed on the basis of subsequent observations (see, for example, Langhorne, unpublished). The two most likely mechanisms at the present time are turbulence effects at the ice-water interface, and in-plane strain effects. These are discussed in the following sections.

\section{Current activity}

Many of the studies referred to in the introduction reported a close relationship between $c$-axis orientation and current flow. In particular, the preferred $c$-axis alignment was correlated with the direction of observed or inferred current movement at the ice-water interface. Our data generally support the notion that current activity can lead to the development of aligned columnar sea ice, although the current measurements acquired from site B suggest that other processes may also be locally responsible.

The presently accepted model for alignment suggests that aligned columnar sea ice develops by the favored growth of crystals whose basal planes lay perpendicular to the direction of current movement (Weeks and Gow, 1978). This theory was presented as follows. 
As an ice sheet develops, brine is excluded from the ice structure and accumulates at the growing interface. This brine layer slows the growth of the columnar grains, and forces them to develop a dendritic structure in the direction of the basal planes. Directional current activity at the growing interface can deplete this brine layer by creating eddy currents at the tips of the growing dendrites; however, the process is directionally selective, and only those platelets oriented perpendicular to the current flow will produce turbulent eddies. Crystals with this geometry therefore enjoy a growth advantage over their neighbors, and will slowly "wedge out" their competition with depth. In the end, the ice sheet will develop a $c$-axis alignment which lies parallel to the current and strengthens with depth.

In general, our field data neither support nor refute this model, although a recent theoretical analysis has suggested that $c$-axis alignments should require $6-7 \mathrm{~d}$ to develop by this process (Langhorne and Robinson, 1986). Given that the rate of ice growth calculated for Pond Inlet is correct, this value would place the inception of $c$-axis alignment at a depth of approximately $25 \mathrm{~cm}$, rather than the $4 \mathrm{~cm}$ observed in the field.

One way to account for this discrepancy is to consider the possible effect of grain-size on alignment. If Weeks and Gow's model is applicable, then the time required for $c$-axis alignment to occur should depend on the grain-size at the time of current activity. For example, if directional fluid flow is active during nucleation, then alignment may be almost instantaneous, as the crystals which are most favorably oriented will quickly wedge out those less favorably oriented. The analysis of Langhorne and Robinson (1986) does not take this possibility into consideration.

Secondly, we have found that aligned and non-aligned columnar sea ice can develop side by side in the field, as in the pack-ice region located just east of Pond Inlet in 1983. In this area, the vast majority of ice floes were underlain by non-aligned sea ice, while the surrounding new ice sheet consisted of strongly aligned sea ice. This parallels earlier reports that non-aligned sea ice may occur in regions normally underlain by directional currents (Paige, 1966; Reimer, unpublished), and suggests that current activity alone may not be sufficient for the development of aligned columnar sea ice.

\section{Strain as an alignment mechanism}

While current flow appears to be a viable means of producing aligned columnar sea ice, there are situations in which a current-alignment mechanism cannot be applied. These include ice sheets immediately adjacent to tension cracks and ridges (Paige, 1966; Peyton, 1966; Reimer, unpublished), and ice covers underlain by non-directional current activity, as described in this paper. In each of these cases, the $c$-axis alignment appears to lie parallel to the inferred direction of compression in the ice sheet.

Peyton (1966) was first to cite deformation as a possible mechanism of $c$-axis alignment, followed shortly after by Paige (1966). However, it was not until 1980 that a possible model was suggested (Stander and Gidney, 1980). This model was based on the classical dislocation slip theories of Taylor (1938) and Bishop and Hill (1951), and was presented as follows.

Consider an ice cylinder which is undergoing plastic deformation by shear acting along discrete lattice planes (Fig. 7a). If the triangular weight attached to the base of this cylinder is heavy enough to initiate shear along these planes, the body will elongate; however, the manner in which elongation occurs will depend on the environment of deformation.

In Figure $7 \mathrm{~b}$, the cylinder has been allowed to deform in a non-constrained manner by simple shear along the lattice planes. As a result, the cylinder has elongated and rigidly rotated away from the vertical, yet the lattice planes themselves have not rotated with respect to their original orientations. This type of deformation may only occur if the cylinder is totally unconstrained and is therefore free to rotate.

If, on the other hand, the ice cylinder is constrained during deformation, elongation will still be able to occur provided that the lattice planes themselves take up the rotation (Fig. 7c). This is the typical form of deformation found in sea ice, where each crystal is constrained by the

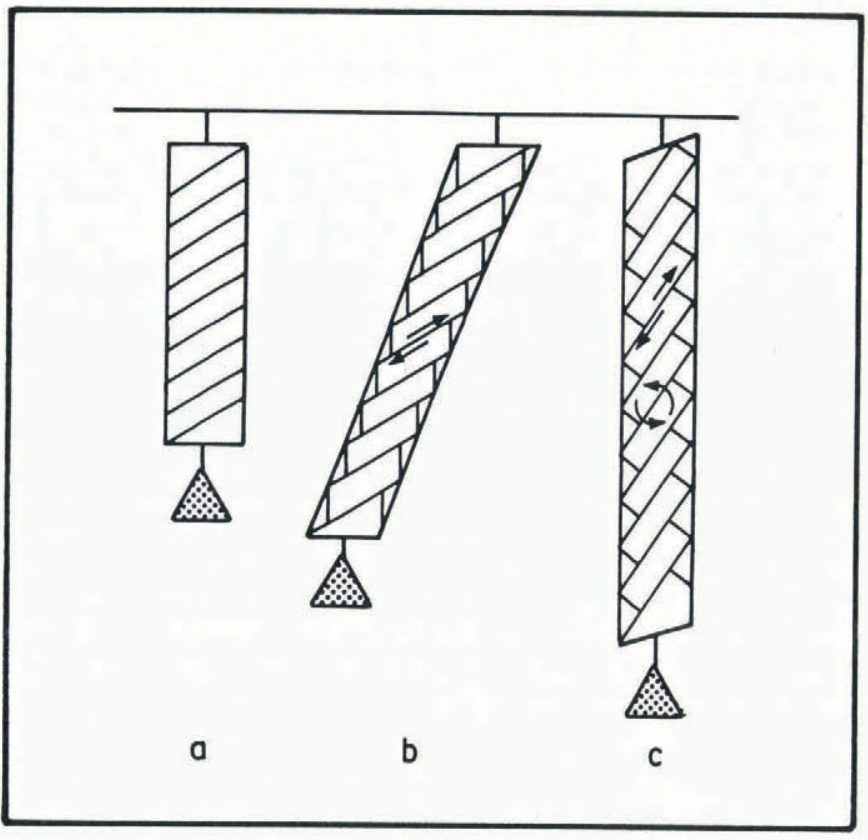

Fig. 7. The rotation of slip planes according to the Taylor-Bishop-Hill model. See paper for discussion.

grains which surround it. In such aggregates, cohesive deformation by lattice slip will produce a crystallographic preferred orientation as the shearing planes rotate towards the plane of maximum elongation.

In sea ice, the only lattice directions known to slip easily lie within the basal planes, although there is evidence that prismatic slip may occur in regions of high strain (Gold, 1963; Muguruma and Higashi, 1963). This leads to complications in applying a strain-alignment mechanism to ice, since polycrystalline aggregates theoretically require five independent slip systems to deform cohesively (Taylor, 1938). However, recent theoretical and experimental investigations have shown that Taylor's criterion may be relaxed when applied to naturally deformed materials. Hobbs (1986) and VanHoutte and Wagner (1986) have both noted that plastic deformation to moderate strains may be accomplished with three independent slip systems, while Gold (1963) has argued that the in-plane deformation of columnar ice should only require two slip systems, provided that these lie in the plane of the deformation.

Computer simulations based on the Taylor-Bishop-Hill model have shown that basal slip in hexagonal crystals will produce a $c$-axis alignment in the direction of maximum shortening similar to that noted in aligned columnar sea ice (Lister and others, 1978). Experimental studies of polycrystalline ice have further confirmed this geometry, and have shown that well-developed $c$-axis alignments can develop after strains of $7-8 \%$ (Jacka, 1982).

Notwithstanding these arguments, measurements acquired during the Pond Inlet study do not support a strainalignment mechanism. Strain during the study period was small (in the order of $0.2-0.3 \%$ ), and the direction of maximum shortening lay $50^{\circ}$ from the measured $c$-axis orientation. However, given that all of these values were acquired after the period of $c$-axis alignment, a strainalignment mechanism may still be applicable provided that strains were adequately large during the first days of ice formation.

According to the displacement data presented in Figure 2, ice movement at Pond Inlet can be separated into two components: an offshore component and a shoreparallel component. Offshore movement probably resulted from the adfreezing of ice within tidal leads during the falling tide, and the re-closing of these leads during the rising tide (Stander and others, 1988). Shore-parallel movement probably occurred as a result of current drag on the ice cover, and decreased logarithmically over time as the ice sheet thickened and became less succeptible to plastic deformation. 
During the first 2 weeks of ice formation, offshore ice movement was negligible, and shore-parallel movement was extreme. Extrapolations from displacement data acquired over the 1982-83 and 1983-84 winters suggest that shoreparallel ice movement during the first days of ice formation may have been in the order of $2-3 \mathrm{~m}$ (Fig. $2 \mathrm{~b}$ ). If so, the strains suffered by the ice sheet in contact with Bergs 1 and 2 may have easily attained values of $6-8 \%$ within $1-2 \mathrm{~d}$ of freeze-up.

Once strain alignment occurs, it is then hypothesized that the orientation will remain constant to the base of the ice sheet, as each crystal grows in continuity with its deformed counterpart.

This situation has recently been modeled using a finiteelement approach by Hamza (personal communication), who has noted a reasonable agreement with our $c$-axis data in those parts of the ice sheet in contact with a fixed iceberg, and a general disagreement outside of these areas. This suggests that, in order for the strain-alignment model to apply, we must define a threshold value beneath which no alignment is possible. Laboratory tests are presently underway to define this value.

\section{CONCLUSIONS}

Two models have been suggested to account for the development of aligned columnar sea ice at Pond Inlet during the winters of $1982-83$ and 1983-84. The first model involves the preferred growth and removal of selected crystals by the application of directional current flow during the first moments after nucleation. The second requires finite strains of $6-8 \%$ during the first days of ice growth. Although both models will require detailed testing under controlled conditions, they appear to fit available field observations on the occurrence and structure of aligned columnar sea ice more exactly than other published models.

\section{ACKNOWLEDGEMENTS}

Financial support for this work was provided from several sources, including the Centre for Cold Ocean Resource Engineering (C-CORE), the Arctic Research Establishment of Pond Inlet, and Mobil Oil. Field support and lodging were graciously provided by $\mathrm{H}$. and S. Steltner of the Arctic Research Establishment.

\section{REFERENCES}

Bishop, J.F.W. and R. Hill. 1951. A theory of plastic distortion of a polycrystalline aggregate under combined stresses. Philos. Mag., 44, 414-417.

Cherepanov, N.V. 1971. Spatial arrangement of sea ice crystal structure. Probl. Arct. Antarct., 38, 176-181.

Gold, L.W. 1963. Deformation mechanisms in ice. In Kingery, W.D., ed. Ice and snow. Cambridge, MA, M.I.T. Press, 8-27.

Gow, A.J. S.F. Ackley, W.F. Weeks, and J.W. Govoni. 1982. Physical and structural characteristics of Antarctic sea ice. Ann. Glaciol., 3, 113-117.

Jacka, T.H. 1982. Laboratory studies of the creep of polycrystalline ice - the effects of crystal size and the development of orientation fabrics. In Sixth International Symposium on the Physics and Chemistry of Ice. University of Missouri - Rolla, August 2-6, 1982, 30-31.

Hobbs, B.E. 1986. The geological significance of microfabric analysis. In Wenk, H.R., ed. Preferred orientation in deformed metals and rocks: an introduction to modern texture analysis. New York, Academic Press, 463-484.

Langhorne, P.J. Unpublished. Crystal alignment in sea ice. (Ph.D. thesis, Cambridge University, 1982.)

Langhorne, P.J. and W.H. Robinson. 1986. Alignment of crystals in sea ice due to fluid motion. Cold Reg. Sci. Technol., 12(2), 197-214.

Langhorne, P.J., J.R. Rossiter, and T.E. Keliher. 1980. Remote estimation of the properties of sea ice, ice core analysis, Beaufort Sea, March 1979. C-Core Publ. 80-7.
Lister, G.S., M.S Paterson, and B.E. Hobbs. 1978. The simulation of fabric development during plastic deformation and its application to quartzite: the model. Tectonophysics, 45, 107-158.

Muguruma, J. and A. Higashi. 1963. Non-basal glide bands in ice crystals. Nature, 198(4880), 573.

Paige, R.A. 1966. Crystallographic studies of sea ice in McMurdo Sound, Antarctica. Port Hueneme, CA, U.S. Naval Civil Engineering Laboratory. (Technical Report R494.)

Parsons, B.L., J.B. Snellen, and B. Hill. 1986. Physical modeling and the fracture toughness of sea ice. In Lunardini, V.J., Y.S. Wang, O.A. Ayorinde, and D.V. Sodhi, eds. Proceedings of the Fifth International Mechanics and Arctic Engineering (OMAE) Symposium .... Tokyo, Japan, April 13-18, 1986 ... Vol. 4. New York, American Society of Mechanical Engineers, 358-364.

Perey, F.G.J. and E. Pounder. 1958. Crystal orientation in ice sheets. Can. J. Phys., 36(4), 494-502.

Peyton, H.R. 1966. Sea ice strength. Fairbanks, AK, University of Alaska. Geophysical Institute. (Reports Series UAG-R-182.)

Reimer, E.M. Unpublished. Field testing of fast ice in Eclipse Sound, Baffin Island. C-Core Data Report, 1982.

Schwarzacher, W. 1959. Pack-ice studies in the Arctic Ocean. J. Geophys. Res., 64(12), 2357-2367.

Serikov, M.I. 1964. Structure of Antarctic sea ice. Sov. Antarct. Exped. Inf. Bull., 4(5), 265-266.

Smith, D.D. 1964. Ice lithologies and structures of ice island Arlis II. J. Glaciol., 5(37), 17-38.

Stander, E.J. 1985. The use of subgrains as paleostress indicators in first year sea ice. In POAC 85; the 8th International "Conference on Port and Ocean Engineering under Arctic Conditions, Narssarssuaq, Greenland. September 7-14, 1985. Proceedings, Vol. 1. Horsholm, Danish Hydraulic Institute, 168-176.

Stander, E.J. Unpublished. The effects of deformation and time on the structure of sea ice, Pond Inlet, N.W.T. Report prepared for National Research Council of Canada, 1983.

Stander, E.J. and G.A. Gidney. 1980. The measurement of finite strain in sea ice by impulse radar techniques. C-Core Publ. 80-21, 127-164.

Stander, E.J., R.M.W. Frederking, and J.P. Nadreau. 1988. The effects of tidal jacking on ice displacement and strain in the nearshore environment. AIHR Symposium. Sapporo, Japan, August 1988. Vol. 1, 526-537.

Taylor, G.I. 1938. Plastic strain in metals. J. Inst. Met., 62, 307-324.

Tucker, W.B., A.J. Gow, and W.F. Weeks. 1985. Physical properties of sea ice in the Greenland Sea. In POAC 85; the 8th International Conference on Port and Ocean Engineering under Arctic Conditions, Narssarssuaq, Greenland, September 7-14, 1985. Proceedings, Vol. 1. Horsholm, Danish Hydraulic Institute, 177-188.

Urabe, N. and M. Inoue. 1986. Mechanical properties of Antarctic sea ice. In Lunardini, V.J., Y.S. Wang, O.A. Ayorinde, and D.V. Sodhi, eds. Proceedings of the Fifth International Mechanics and Arctic Engineering (OMAE) Symposium .... Tokyo, Japan, April 13-18, 1986 ... Vol. 4. New York, American Society of Mechanical Engineers, 303-309.

VanHoutte, P. and F. Wagner. 1986. Development of textures by slip and twinning. In Wenk, H.R., ed. Preferred orientation in deformed metals and rocks: an introduction to modern texture analysis. New York, Academic Press, 463-484.

Vittoratos, E.S. 1979. Existence of oriented sea ice by the Mackenzie Delta. In POAC 79; the Fifth International Conference on Port and Ocean Engineering under Arctic Conditions ..., August 13-18, 1979. Proceedings, Vol. 1. Trondheim, University of Trondheim, 643-650.

Wang, Y.S. 1979. Crystallographic studies and strength tests of field ice in the Alaskan Beaufort Sea. In POAC 79, the Fifth International Conference on Port and Ocean Engineering under Arctic Conditions .... August 13-18 1979. Proceedings, Vol. 1. Trondheim, University of Trondheim, 651-665.

Weeks, W.F. and A.J. Gow. 1978. Preferred crystal orientations in the fast ice along the margins of the Arctic Ocean. J. Geophys. Res., 83(C10), 5105-5121. 
Weeks, W.F. and A.J. Gow. 1980. Crystal alignments in the fast ice of Arctic Alaska. J. Geophys. Res., 85(C2), $1137-1146$.
Weeks, W.F. and O.S. Lee. 1958. Observations on the physical properties of sea-ice at Hopedale, Labrador. Arctic, 11(3), 135-155.

MS. received 23 February 1988 and in revised form 21 February 1989 